https://doi.org/10.48009/1_iis_2005_289-295

\title{
AN INVESTIGATION OF SELF-REPORTED COMPUTER LITERACY: IS IT RELIABLE?
}

\author{
Dr. Kimberly Merritt, Cameron University, kmerritt@ cameron.edu \\ K. David Smith, Cameron University, davids@cameron.edu \\ John C. Di Renzo, Jr., Cameron University, johnd@cameron.edu
}

\begin{abstract}
Research in management information systems often examines computer literacy as an independent variable. Study subjects may be asked to self-report their computer literacy and that literacy is then utilized as a research variable. However, it is not known whether self-reported computer literacy is a valid measure of a subject's actual computer literacy. The research presented in this paper examined the question of whether self-reported computer literacy can be a reliable indication of actual computer literacy and therefore valid for use in empirical research. Study participants were surveyed and asked to self-report their level of computer literacy. Following, subjects were tested to determine an objective measure of computer literacy. The data analysis determined that self-reported computer literacy is not reliable. Results of this research are important for academic programs, for businesses, and for future empirical studies in management information systems.
\end{abstract}

Keywords: Computer literacy, self-assessment, student computer knowledge

\section{INTRODUCTION}

The level of computer literacy is an important variable in a number of settings. In the management information systems (MIS) curriculum at the university at which the authors are employed, students are asked to self-report their level of computer literacy. Based on the level of self-reported literacy, students are directed to enroll in introductory computer courses, or are directed to enroll directly in the first course of the MIS curriculum. In talking with faculty at peer institutions, the authors have learned that this system of placement is utilized at other universities.

This system of student placement has produced a number of problems. First, some students seem to under-report their level of literacy and therefore are directed to enroll in the introductory computer course when it is not needed. Other students are over-confident concerning the level of their computer literacy and are directed to enroll directly in the first course of the MIS curriculum without the foundation in computer concepts that is necessary for success in the course. Both of these scenarios result in misplacement of the students in question.

Self-reported computer literacy also presents problems in academic research. Research in MIS and related fields often examines computer literacy as an independent variable. Study subjects may be asked to self-report their computer literacy and that literacy is then utilized as a research variable. However, it is not known whether self-reported computer literacy is a valid measure of a subject's actual computer literacy. This leads to questions about the soundness of any research 
results. Therefore, as both researchers and classroom instructors, the reliability of self-reported computer literacy intrigued the authors.

\section{LITERATURE REVIEW}

The purpose of this section is to examine what is already known about the need for computer literacy. Review of the literature was based on three broad areas of current research interest. These included the importance of computer literacy in business, education and research.

\section{Computer Literacy in Business}

General agreement exists that most companies, and especially Fortune 500 companies, have an ever increasing need for computer literate (information technology literate) personnel at all levels of the organization [11]. This is due in part to a shift to a services economy and to the emergence of the Internet as a viable e-commerce technology [11]. To meet this demand, individual companies, such as Ford Motor Company, and the Federal Government, invest in expensive training and grant programs $[6,1]$.

Other research in the area of computer literacy strongly supports the need for Information Technology (IT) literacy as a means to achieve success in the job market [3]. Computer literacy requirements transcend the simple ability to use common software packages. Rather, computer literacy implies an ability to understand how information processing supports business from an "Enterprise-wide" perspective [3].

\section{Computer Literacy in Education}

Research in the area of education focuses on self-reported computer literacy skills, the relationship between computer skills and scholastic performance and computer skills assessments for teachers. General consensus exists that computer literacy skills are required. However, some research is decidedly negative about computer literacy as a measure of educational success. For instance Andrew Nikiforuk [9] argues that "research indicates that it (computer literacy) provides no significant improvement over traditional forms of education". Other authors take the opposite view. In fact many educators now accept the idea that responsible educators must prepare students for the future; therefore, information technology must be a part of the educational landscape [8]. Others argue that technology must be integrated into the educational environment in a much wider context. This includes uses of technology in the classroom and positive attitudes that help technology succeed [4].

Finally, an apparent discrepancy exists between the need for teaching computer literacy skills and the computer literacy skill sets of teachers, and that has changed little over several years. Sheffield [10] reported that many pre-service teachers report little experience with commonly used programs with the exception of word processing software. Authors of another study [2] indicate that use of technology as related to pedagogical practices demonstrates that only a small percentage of teachers have adequate technical information and communications skills. 


\section{Computer Literacy in Research}

The level of computer literacy of research participants is often utilized in academic research as an independent variable. For example, Merritt [7] conducted an investigation of user satisfaction in data warehousing. Results were analyzed based on the level of self-reported computer literacy. The results found that those users who classified themselves as "expert user" were the least satisfied of the system users. However, in discussing the results of the research, the author points out that there is no academic evidence that self-reported computer literacy is reliable. Therefore, the ability to draw conclusions from the data was limited.

There has been one academic study investigating the ability of students to accurately report their level of computer literacy. Larres, Ballentine and Whittington [5] conducted a study to determine if undergraduate accounting students could reliably self-assess computer literacy. The results reveal significant differences in the students' perceived and actual computer literacy with the vast majority of students over-estimating their level of computer abilities. However, the findings indicate that self-assessment stimulates reflection and contributes to lifelong learning. The authors concluded that a self-assessment of computer literacy should not be used in isolation.

\section{PURPOSE OF THE STUDY}

The purpose of this study was to investigate the reliability of self-reported computer literacy. The study utilized a two-phase data gathering approach to compare self-reported computer literacy to an objective measure of computer literacy.

\section{METHODOLOGY}

In the first stage of data gathering, subjects were asked to self-report their computer literacy by completing a simple questionnaire. The survey gathered general demographic data, along with number years of computer usage and a self-reported level of general computer literacy. Following, subjects were asked to rate their level of literacy in various computer software applications and with hardware components. The areas of literacy included: computer hardware, systems software, word processing programs, database programs, and spreadsheet software, among others.

Following the survey, subjects were asked to complete an objective measure of computer literacy. For this data gathering phase, an interactive tool was utilized. SAM Challenge is a product of Thomson publishing and is a computer-based computer literacy test. The product contains multiple sections to test subject knowledge in specific applications. It is a web-based, hands-on performance evaluation tool. The sophisticated tool allows subjects to be tested on their understanding of computer concepts, but also contains performance-based items to test the application of those concepts.

To develop the objective measure, the researchers contacted both peer institutions and flag-ship institutions to request information on any computer literacy tests employed by these institutions. Limited cooperation was received. Those institutions willing to share the content of their computer literacy instruments were asked to provide a copy to the researchers. This bench- 
marking provided a foundation for what concepts and tasks should be included in the objective test, thus providing content validity for the instrument.

Students who were enrolled in the first course of the MIS curriculum were utilized as subjects for this research for three strong reasons. First, the students in the first course of the MIS curriculum were those students who were most of interest to the researchers. It is these students who must determine, based on their self-determined computer literacy, whether to take the introductory computer courses. Should the results of this research lead to a change of policy at the university, it these students who will be most affected. Second, students in the MIS curriculum are required to be computer literate. Therefore, it was expected that those students would have enough experience with computer concepts to self-report their level of computer literacy. Finally, this course is a requirement for all business majors. Therefore, utilizing students in this course provided a variety of backgrounds and interests.

Data from the two phases were gathered and compared to determine if the self-reported computer literacy provided a reliable prediction of the objective measure of computer literacy.

\section{DATA ANALYSIS}

Over two semesters, sixty-eight students volunteered to take the survey and follow-up with the SAM Challenge exam that measured their expertise in Microsoft software applications. Of these sixty-eight volunteers, fifty-five (or $81 \%$ ) actually participated in the research.

The null hypothesis for this study is as follows:

$$
\begin{aligned}
\mathrm{H}_{\mathrm{o}}= & \text { There is no statistically significant difference between a student's self-reported } \\
& \text { computer literacy and the objective measure of the student's computer literacy. }
\end{aligned}
$$

A paired t-test was run using student responses to a written survey and their actual scores from the SAM Challenge objective exam. Based on this small sample, at the $95 \%$ confidence interval, there is a statistically significant difference between the reported values and the students' actual scores $(\mathrm{P}=0.006)$ (see Table 1 and Figure 1 below). Consequently, the data show that students do not accurately report their level of computer literacy.

Table 1. Paired T for SR Exp - Act Exp

\begin{tabular}{lllll} 
& N & Mean & StDev & SE Mean \\
\hline SR & 55 & 2.164 & 0.788 & 0.106 \\
Actual & 55 & 1.873 & 0.610 & 0.082 \\
Difference & 55 & 0.291 & 0.762 & 0.103
\end{tabular}

95\% CI for mean difference: $(0.085,0.497)$

$\mathrm{T}$-Test of mean difference $=0($ vs not $=0): \mathrm{T}$-Value $=2.83 \mathrm{P}-$ Value $=0.006$ 


\section{Boxplot of Differences}

(with $\mathrm{Ho}$ and $95 \% \mathrm{t}$-confidence interval for the mean)

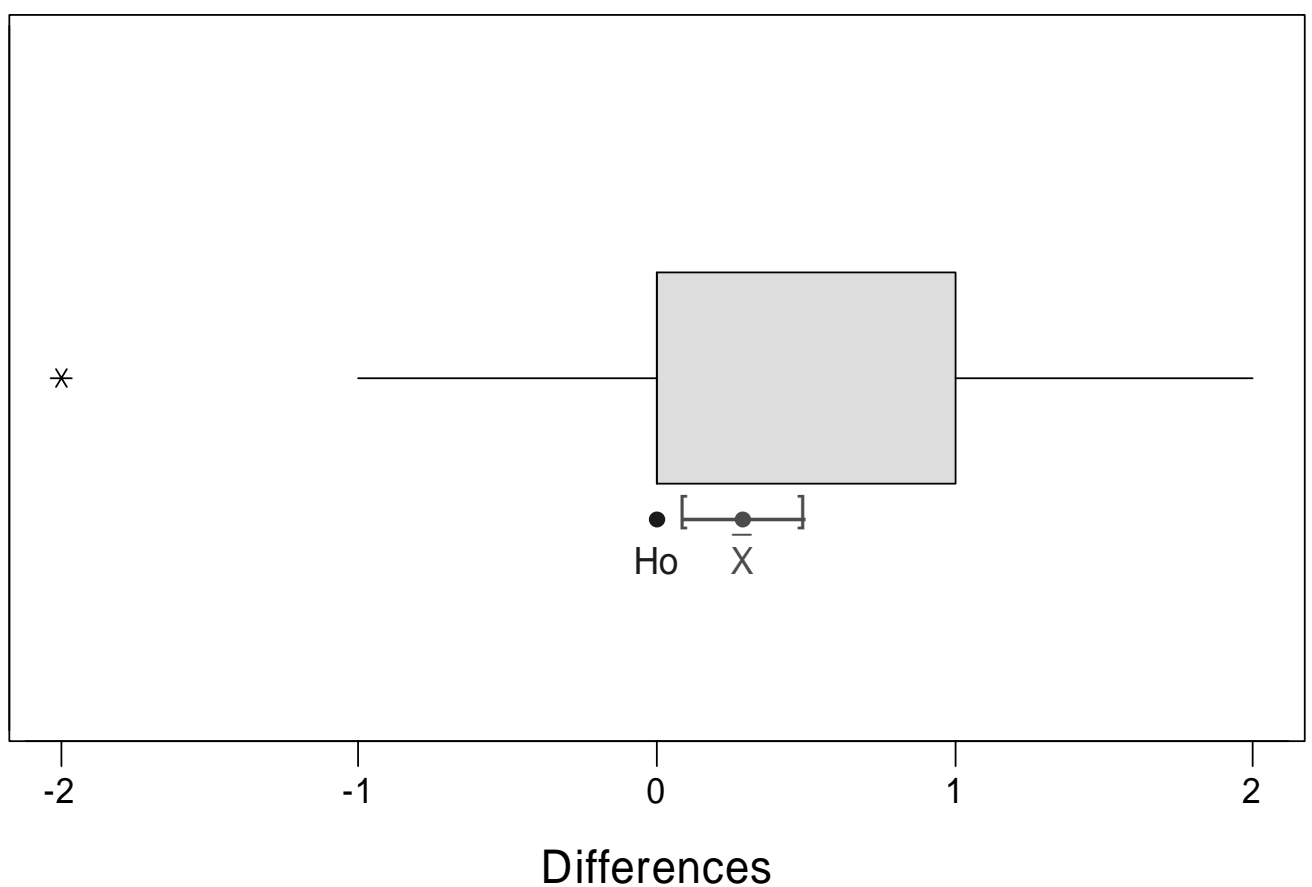

Figure 1. Differences Between Students' Reported and Actual Scores

\section{IMPLICATIONS OF THE FINDINGS}

The authors have long suspected that self-reported computer literacy is unreliable. The system of student placement in MIS at the authors' institution produces a number of problems for both students and faculty as discussed above. Also, the use of self-reported computer literacy as an independent variable in research is common. Although more research is needed, this research gives an indication that self-reported computer literacy is not reliable.

These findings are important in three settings. First, in education, the use of an objective measure of computer literacy is vital. At the university at which the authors teach, based on this research, the use of objective testing of computer literacy is being discussed to replace the current system that is based self-reported computer literacy. The testing will involve expense in both time and money, but the benefit will be accurate placement of students.

These findings have implication for businesses as well. Potential job candidates are often asked to indicate a level of computer literacy, or a level of computer literacy is often assumed. However, based on these results, businesses may want to employ an objective measure of computer literacy as well. As discussed below, future research will investigate computer literacy among employees and job seekers. 
Finally, the implications of these results are very important to academic research. Many studies utilize computer literacy, or computer expertise, as an independent variable. For example, Merritt [7] investigated user satisfaction with a data warehouse system. In that research, satisfaction among users of various levels of expertise was compared. If, however, self-reported expertise is not reliable, then future studies would need to objectively measure levels of literacy or expertise.

\section{LIMITATIONS}

The primary limitation of this study was the small sample size. Also, the study utilized students from only one major (business) and all students were attending one university.

\section{FUTURE RESEARCH}

The researchers have identified some possible directions for future research. First, the study needs to be repeated with a larger sample size and one containing a broad spectrum of college majors. In addition, it can be expanded to more populations. This study focused on the reliability of self-reported computer literacy among collage students; in future research, it would be interesting to study both current employees in companies and job applicants.

Also, the data needs to be analyzed to determine if subjects are more able to accurately report computer-literacy in certain areas or applications more than in others. For example, subjects might be able to more accurately report word-processing literacy than general computer literacy.

\section{CONCLUSION}

Computer literacy continues to gain importance in education, business, and research. In many cases, students, job applicants, and research subjects are asked to self-report their level of computer literacy. However, little academic research has investigated the reliability of selfreported computer literacy. This study attempted to contribute to the academic literature by investigating the reliability of self-reported computer literacy. In this study, the data indicate that students are not able to accurately report their computer literacy. More research is needed, but this research should pose a caution to those institutions and those researchers who are currently relying on self-reported levels of computer literacy for any decision-making.

\section{REFERENCES}

1. Brown, S. (2000). Ford's plan to cultivate computer literacy. Electronic Business, 26(4), 138.

2. Hakkarainen, K., Muukonen, H., Lipponen, L., Liomaki, L., Rahikainen, M. \& Lehtinen, E. (2001). Teachers' Information and Comminication Technology (ICT) Skills and Practices of Using ICT. Journal of Technology and Teacher Education, 9(2), 181-197.

3. Kanter, J. (1996). Guidelines for attaining information literacy. Information Strategy, 12, 611.

4. Kosakowski, J. (1998). The benefits of information technology. ERIC Digest. Retrieved February 8, 2005 from the ERIC database.

5. Larres, P., Ballantine, J., \& Whittington, M. (2003). Evaluating the validity of selfassessment: Measuring Computer Literacy Among Entry-level Undergraduates within 
Accounting Degree Programmes at two UK Universities. Accounting Education, 12(2), 97112.

6. McManus, T. (2000). New definition of tech support: teaching basic skills in new economy. Crain's Chicago Business, 23(10), SR8 - SR9.

7. Merritt, K. (2003). User Satisfaction in Data Warehousing: An Empirical Investigation of Salient Variables. Unpublished doctoral dissertation, Argosy University, Sarasota, Florida.

8. Murray, J. \& Kinnick, N. (2003). Contemporary Literacy: Essential Skills for the $21^{\text {st }}$ Century, Multimedia Schools 10(2), 15-18.

9. Nikiforuk, A. (2000). Digital dunderheads: let's can this nonsense about computer literacy tests in schools. Canadian Business, 73(4), 12-14.

10. Sheffield, C. (1996). An examination of self-reported computer literacy skills of pre-service teachers. Action in Teacher Education, 17, 45-52.

11. Zhao, J. \& Alexander, M. (2002). Information technology skills recommended for business students by Fortune 500 executives, Delta Pi Epsilon Journal 44(3), 175 - 189. 